\title{
Article \\ Gastrocnemius Activation throughout the Competitive Season in Athletes of Different Experience Levels
}

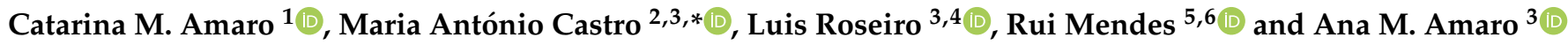 \\ 1 University of Coimbra, 3004-531 Coimbra, Portugal; catarinammamaro@gmail.com \\ Polytechnic of Coimbra, ESTeSC, 3046-854 Coimbra, Portugal \\ 3 Department of Mechanical Engineering, University of Coimbra, CEMMPRE, 3030-788 Coimbra, Portugal; \\ lroseiro@isec.pt (L.R.); ana.amaro@dem.uc.pt (A.M.A.) \\ 4 Polytechnic of Coimbra, ISEC, 3030-199 Coimbra, Portugal \\ 5 Polytechnic of Coimbra, ESEC, 3030-329 Coimbra, Portugal; rmendes@esec.pt \\ 6 University of Coimbra, CIDAF, 3040-248 Coimbra, Portugal \\ * Correspondence: mac@estescoimbra.pt; Tel.: +351-239802430
}

Citation: Amaro, C.M.; Castro, M.A.; Roseiro, L.; Mendes, R.; Amaro, A.M Gastrocnemius Activation throughout the Competitive Season in Athletes of Different Experience Levels. Appl. Sci. 2021, 11, 984. https://doi.org/ 10.3390/app11030984

Academic Editor: Shane Malone Received: 23 December 2020

Accepted: 18 January 2021

Published: 22 January 2021

Publisher's Note: MDPI stays neutral with regard to jurisdictional claims in published maps and institutional affiliations.

Copyright: (c) 2021 by the authors. Licensee MDPI, Basel, Switzerland. This article is an open access article distributed under the terms and conditions of the Creative Commons Attribution (CC BY) license (https:// creativecommons.org/licenses/by/ $4.0 /)$.

\begin{abstract}
Basketball is a team sport in which the players undergo rapid reactions, and running efforts are usually carried out in all directions. The main goal of the present study was to evaluate the muscle activity response in different basketball movements, considering two types of athletes with different levels of experience. Using a group of nine volunteers, female athletes from a senior basketball team, a data acquisition protocol was defined to identify the changes that occurred throughout the sports season. In this study, to assess the gastrocnemius muscle activity, intensity peak (\%MC) and time to peak (TP) were evaluated for five typical basketball skills and movements involving running and jumping with and without the ball. Seven repetitions were executed for each movement, performed at two different time-points of the sports season: at the beginning of the teams' competition, in November (T1), and at the season peak, in March (T2). TP presents greater values for T2 of the season when compared with $\mathrm{T} 1$. The results show that the level of experience of the athletes has a significant effect on the results of TP and \%MC, particularly when comparing the two seasons.
\end{abstract}

Keywords: basketball; electromyography; stage of training; sports biomechanics; basketball moves

\section{Introduction}

Regular sports activity improves skeletal muscle function and cardiovascular health, as well as prevents and reverses obesity, reduces anxiety and depression, and improves selfconfidence and cognitive function [1,2]. Basketball involves frequent jumping, accelerating, decelerating, turning, and pivoting [3]. It is a team game during which players experience up to 105 high-intensity activities of short duration (2-6 s), occurring on average every $21 \mathrm{~s}$. This suggests that, for basketball players, the ability to repeat high-intensity efforts such as sprints with and without a ball is very important [4]. Running efforts in basketball are usually carried out in all directions, with short and intense actions, with long and moderate activity and recovery, which can induce injuries [5-7]. Running while dribbling a ball is a fundamental basketball skill, and better players can distinguish themselves by experiencing less loss of contact with the ball while running [8]. A higher number of people participating in such a physically demanding sport can result in an increased risk of injury [9]. In recent years, the number of basketball players has increased, as well as the likelihood of injuries. To avoid the incidence of injuries, the use of strategies that include pre-season conditioning, functional training, and strength and balance programs should be considered, which must be continued and adjusted throughout the game season [10,11]. Several authors have evaluated the probability of injuries during basketball games [5,12-14]. The most common injuries that occur in basketball players are in lower extremities $[5,15]$, posing a major risk for the ankle and knee [16]. According to Klyne et al. [17], gastrocnemius is one of three 
primary muscles spanning the ankle and the knee joint, which is why it becomes important to know how these muscles respond during a sports activity. Greater gastrocnemius forces during landing are associated with an increase in joint stiffness, protecting the joint from external loading and injury risk [18]. Various authors [19-21] have highlighted that ankle injuries are the most common injuries in basketball players because it is a sport that combines running and jumping. Longo et al. [22] proposed a program to prevent injuries in elite male players' basketball. There are a lot of movements during a basketball game, like shots, free-throws, passes, dribbling, and rebounding. Recovering the ball after a shot, usually called rebound, is of particular interest since almost half of all basketball-related foot and ankle injuries occur during this movement [19]. As well as this, the effect of cutting promotes ankle inversion sprains, which represent the most common type of ankle injury in basketball [12,23]. Vieira et al. [24] performed a study in which they showed that a substantial medial gastrocnemius torque contribution tended to rotate up the medial aspect of the foot (ankle inversion). Although there are different methods for measuring muscle activation, such as visible light and infrared, the golden standard is electromyography [25]. In basketball players, surface electromyography (sEMG) is commonly used to measure the bioelectrical activity of muscles, especially for the upper limbs, during free throws. sEMG can contribute to the diagnosis of injuries because it makes it possible to obtain an electrical signal from a muscle during a body movement, and the degree of muscular activity shows the muscular level effort [26]. Henry et al. [27] used sEMG to assess gastrocnemius activity and verified a consistent medial gastrocnemius response to surface disturbances, which induces ankle flexion-inversion movements. Sanderson et al. [28] conducted a study using sEMG to assess the gastrocnemius response during a pedaling cadence and observed that the greatest changes in gastrocnemius length occurred during the recovery phase, when the muscles showed little excitement. The free throw is the principal activity evaluated by sEMG in basketball players to verify the relationship between the accuracy and the muscle activity [29-31]. SEMG is also used to evaluate the flexor carpi radialis (forearm) and the triceps brachii (upper arm) in the case of dribbling during basketball [32]. sEMG is also used in wheelchair basketball players to estimate the muscle activity in upper limbs, in the elbow flexor muscles, namely, biceps brachii longus, biceps brachii brevis, and brachioradialis $[33,34]$. During sEMG, the maximum muscle activation is used to identify the muscle contraction, which allows for the normalization of the signal [35]. sEMG is frequently used to evaluate the level of activation of core muscles during suspension exercises [36]. The knowledge of muscle activity during sports practice can help coaches to define appropriate exercises in different stages of the season.

Some studies have reported common injuries in basketball players. However, the literature does not present any work about the use of sEMG in evaluating the gastrocnemius activity during different basketball movements, considering different sports season times and athletes with two different experience levels. Therefore, this work intends to study the influence of different movements, season periods, and athletes' levels on the gastrocnemius activity and contribute to developing knowledge that helps coaches and sport professional staff develop a training plan to avoid the occurrence of injuries.

\section{Materials and Methods}

This study considered a group of volunteers, none of whom were professional female basketball athletes, divided into level 1 and level 2 according to their experience, which was defined based on the number of games played and whether the athlete belonged to a regional basketball elite team or not. Initially, the group was formed by 11 athletes; however, during the season, the group was reduced to 9 due to injury and scholarly reasons.

This study was approved by the local ethics committee and was performed according to the Declaration of Helsinki, with all the participants' data considered and stored anonymously and confidentially. All subjects were fully informed of the nature of the study and gave written informed consent. Table 1 shows the sample characteristics and their experience level. 
Table 1. Volunteer characteristics.

\begin{tabular}{|c|c|c|c|c|c|c|c|}
\hline Athletes & Age (Years) & Height (m) & Mass (kg) & BMI $\left(\mathrm{kg} / \mathrm{m}^{2}\right)$ & $\begin{array}{l}\text { Dominant } \\
\text { Hand }\end{array}$ & $\begin{array}{l}\text { Years of } \\
\text { Practice }\end{array}$ & $\begin{array}{c}\text { Level of } \\
\text { Experience }\end{array}$ \\
\hline 1 & 19 & 1.79 & 73.05 & 22.8 & Right & 7 & 2 \\
\hline 2 & 19 & 1.66 & 66.96 & 24.3 & Right & 12 & 1 \\
\hline 3 & 19 & 1.71 & 54.97 & 18.8 & Right & 11 & 1 \\
\hline 4 & 22 & 1.64 & 70.47 & 26.2 & Left & 17 & 1 \\
\hline 5 & 23 & 1.69 & 72.26 & 25.3 & Right & 17 & 1 \\
\hline 6 & 21 & 1.58 & 69.90 & 28 & Right & 7 & 2 \\
\hline 7 & 18 & 1.62 & 51.96 & 19.8 & Right & 11 & 2 \\
\hline 8 & 19 & 1.60 & 61.44 & 24 & Right & 6 & 2 \\
\hline 9 & 19 & 1.66 & 52.91 & 19.2 & Left & 11 & 1 \\
\hline Mean \pm SD & $19.9 \pm 1.7$ & $1.66 \pm 0.06$ & $66.96 \pm 8.60$ & $23.2 \pm 3.3$ & - & $11.0 \pm 4$ & - \\
\hline
\end{tabular}

The data acquisitions were performed at two time-points of the sports season, the first one in November (T1), corresponding to the beginning of the season, and the second one in March (T2), corresponding to the peak of the season. Five different movements were considered, namely, running with the ball (RB), running without the ball (RNB), lay-up on the right side (LR), lay-up on the left side (LL), and rebound (R). The rebound was the only movement in these five without having an association with running; however, all these movements recruit the lower limb in different ways. Each athlete performed 7 repetitions of each movement for each test condition, which resulted in a total of 630 valid trial data. To avoid predisposition in the assessment, the test order was randomized. Between movements, the athletes had $1 \mathrm{~min}$ to rest, and between repetitions in the same movement, they had $30 \mathrm{~s}$.

Surface electromyography data were collected via the BioSignalPlux system after skin preparation to decrease the impedance between the skin and the electrode. This telemetric system contains a data acquisition box and Bluetooth communication with the computer. The sensors used to record sEMG amplified signals with a bandwidth of $25-500 \mathrm{~Hz}$, a common-mode rejection ratio of $100 \mathrm{~dB}$, and an input impedance greater than $100 \mathrm{GOhm}$. The surface electrodes $(\mathrm{Al} / \mathrm{AgCl}, \mathrm{AMBU}$ BlueSensor $\mathrm{N})$ were placed aligned with the muscle fiber orientation (center-to-center distance of $22 \mathrm{~mm}$ ) at the most prominent part of the muscle bellies following SENIAM recommendations [37]. The same researcher performed electrode placement. The medial (MG) and lateral gastrocnemius (LG) muscles in both legs were identified through palpation of the muscle belly, with skin shaved, abraded, and cleaned using standard medical alcohol swabs for electrode placement. The reference electrode was placed in the tibial tuberosity (Figure 1). The sEMG data were sampled at $1000 \mathrm{~Hz}$.

To analyze and observe the signal in the OpenSignals software, a frequency amplitude of the signal between 20 and $400 \mathrm{~Hz}$ was used. During the tests, athletes were equipped with sEMG apparatus, supported by a belt, which registered muscle activity. All acquisitions were achieved in the same gym, with the same ball ( 0.62 bar), and using the same basket table. All players used their normal basketball shoes, which were not changed between the two evaluation time-points of the season. In the present study, data normalization was performed in reference to the maximal contraction (\%MC) during the activity [38,39].

Data were analyzed using IBM SPSS software (version 25.0) [40]. Descriptive statistics are presented using mean \pm standard deviation. The normality test of the data was performed with the Shapiro-Wilk test. As the data lacked normality, the Wilcoxon test was used to compare the two assessment time-points (T1 and T2). The Friedman test was considered for multiple non-parametric comparisons between the different levels of athlete experience, muscles, and types of sports movements [41]. The significance level was set at $5 \%$. 

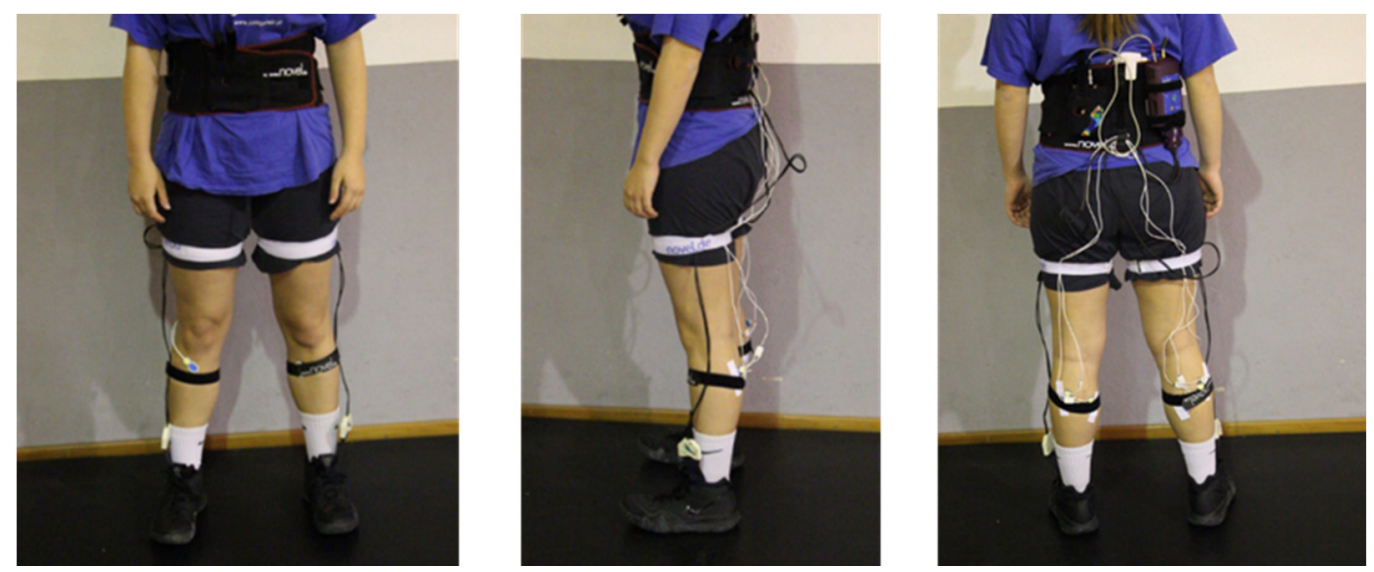

Figure 1. Surface electromyography (sEMG) equipment placed on one of the athletes.

\section{Results}

Table 2 shows the average values $(\bar{X})$ and the standard deviation (SD) of the time to peak of muscle activity (TP) and \%MC at the two time-points of the season, considering each of the five different movements. The results of the statistical analysis $(p)$ of the two season time-points for each muscle and sport movement are also present in Table 2, as well as the comparison between muscles at each season time-point.

Table 2. $\bar{X}$ (the average values) and SD (the standard deviation) of TP (the time to peak of muscle activity) and \%MC (intensity peak) for five movements at two season time-points (T1 and T2).

\begin{tabular}{|c|c|c|c|c|c|c|c|}
\hline \multirow[b]{2}{*}{ Mov. } & \multirow[b]{2}{*}{ Musc. } & \multicolumn{3}{|c|}{ TP (s) } & \multicolumn{3}{|c|}{$\% \mathrm{MC}$} \\
\hline & & $\begin{array}{c}\text { T1 } \\
\bar{X} \pm \text { SD }\end{array}$ & $\begin{array}{c}\text { T2 } \\
\bar{X} \pm \mathrm{SD}\end{array}$ & $p$ & $\begin{array}{c}\text { T1 } \\
\bar{X} \pm \mathrm{SD}\end{array}$ & $\begin{array}{c}\text { T2 } \\
\bar{X} \pm \mathrm{SD}\end{array}$ & $p$ \\
\hline \multirow{5}{*}{$\mathrm{RB}$} & LGL & $0.84 \pm 0.42$ & $0.92 \pm 0.72$ & 0.953 & $83 \pm 15$ & $87 \pm 7$ & 0.441 \\
\hline & MGL & $0.71 \pm 0.40$ & $0.91 \pm 0.71$ & 0.374 & $85 \pm 12$ & $80 \pm 22$ & 0.401 \\
\hline & LGR & $0.67 \pm 0.30$ & $0.88 \pm 0.56$ & 0.173 & $103 \pm 56$ & $87 \pm 11$ & 0.051 \\
\hline & MGR & $0.89 \pm 0.65$ & $1.00 \pm 0.63$ & 0.594 & $78 \pm 18$ & $88 \pm 10$ & 0.214 \\
\hline & $P$ & 0.269 & 0.586 & & 0.615 & 0.512 & \\
\hline \multirow{4}{*}{ RNB } & LGL & $0.81 \pm 0.28$ & $0.96 \pm 0.60$ & 0.594 & $80 \pm 18$ & $86 \pm 9$ & 0.374 \\
\hline & MGL & $0.77 \pm 0.23$ & $0.88 \pm 0.55$ & 0.767 & $82 \pm 11$ & $88 \pm 11$ & 0.025 \\
\hline & LGR & $0.67 \pm 0.20$ & $0.95 \pm 0.50$ & 0.110 & $77 \pm 18$ & $86 \pm 10$ & 0.025 \\
\hline & MGR & $0.79 \pm 0.29$ & $0.88 \pm 0.55$ & 0.859 & $78 \pm 14$ & $88 \pm 9$ & 0.173 \\
\hline \multirow{6}{*}{ LR } & $p$ & 0.506 & 0.145 & & 0.865 & 0.698 & \\
\hline & LGL & $0.66 \pm 0.17$ & $0.73 \pm 0.37$ & 0.678 & $73 \pm 22$ & $84 \pm 7$ & 0.441 \\
\hline & MGL & $0.64 \pm 0.17$ & $0.70 \pm 0.36$ & 0.515 & $82 \pm 9$ & $88 \pm 9$ & 0.123 \\
\hline & LGR & $0.62 \pm 0.08$ & $0.69 \pm 0.18$ & 0.407 & $77 \pm 13$ & $84 \pm 5$ & 0.038 \\
\hline & MGR & $0.76 \pm 0.25$ & $0.80 \pm 0.19$ & 0.515 & $71 \pm 16$ & $80 \pm 19$ & 0.173 \\
\hline & $p$ & 0.053 & 0.129 & & 0.137 & 0.887 & \\
\hline \multirow{4}{*}{ LL } & LGL & $0.78 \pm 0.29$ & $0.75 \pm 0.30$ & 0.678 & $80 \pm 11$ & $84 \pm 8$ & 0.678 \\
\hline & MGL & $0.76 \pm 0.24$ & $0.83 \pm 0.21$ & 0.767 & $84 \pm 9$ & $85 \pm 10$ & 0.953 \\
\hline & LGR & $0.66 \pm 0.23$ & $0.74 \pm 0.22$ & 0.260 & $84 \pm 8$ & $87 \pm 5$ & 0.214 \\
\hline & MGR & $0.67 \pm 0.17$ & $0.81 \pm 0.35$ & 0.441 & $85 \pm 8$ & $88 \pm 10$ & 0.767 \\
\hline \multirow{6}{*}{$\mathrm{R}$} & $p$ & 0.068 & 0.706 & & 0.959 & 0.823 & \\
\hline & LGL & $0.80 \pm 0.95$ & $0.71 \pm 0.17$ & 0.314 & $81 \pm 11$ & $73 \pm 11$ & 0.26 \\
\hline & MGL & $0.91 \pm 0.45$ & $0.91 \pm 0.36$ & 0.953 & $86 \pm 7$ & $86 \pm 08$ & 0.06 \\
\hline & LGR & $0.86 \pm 0.35$ & $0.84 \pm 0.25$ & 0.594 & $80 \pm 15$ & $82 \pm 10$ & 0.594 \\
\hline & MGR & $0.94 \pm 0.32$ & $0.84 \pm 0.17$ & 0.953 & $81 \pm 17$ & $78 \pm 27$ & 0.594 \\
\hline & $p$ & 0.269 & 0.392 & & 0.644 & 0.512 & \\
\hline
\end{tabular}

Mov—movement; RB—running with the ball; RNB—running without the ball; LR—lay-up on the right side; LL—lay-up on the left side; $\mathrm{R}$-rebound; Mus—-muscle; LG—lateral gastrocnemius; MG—-medial gastrocnemius; R—right leg; L-left leg. 
An example of the sEMG raw signal of both legs' lateral and medial gastrocnemius obtained at the two season time-points for one of the movements is illustrated in Figure 2.

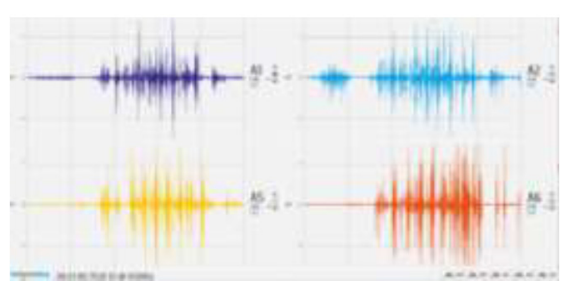

(a)

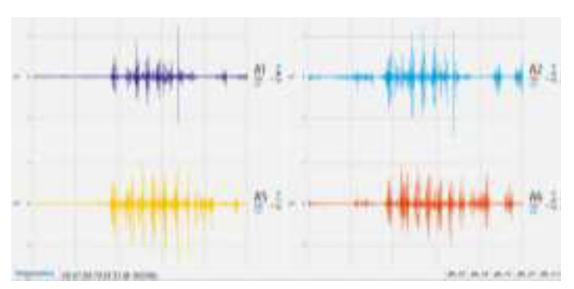

(b)

Figure 2. sEMG raw signal for one of the athletes in the basketball movement running with the ball at the two season time-points: (a) T1, (b) T2.

For the comparisons performed, no statistical differences were found between the two season time-points nor between muscles. To verify if the athletes' level of experience influences the time to peak muscle activity, the players were divided into two groups according to the number of games played and whether they belonged, or not, to the elite regional basketball team. The comparison between the group of more experienced athletes (level $1 ; n=5$ ) with the less experienced ones (level 2; $n=4$ ) was performed for the five movements and the two season time-points (Table 3).

Table 3. $\bar{X}$ and SD of time to peak of muscle activity for the two athlete levels considering the five movements.

\begin{tabular}{|c|c|c|c|c|c|c|c|}
\hline \multirow[b]{2}{*}{ Mov. } & \multirow[b]{2}{*}{ Musc. } & \multicolumn{3}{|c|}{ T1 } & \multicolumn{3}{|c|}{$\mathrm{T} 2$} \\
\hline & & $\begin{array}{l}\text { Level } 1 \\
\bar{X} \pm \text { SD }\end{array}$ & $\begin{array}{c}\text { Level } 2 \\
\bar{X} \pm \text { SD }\end{array}$ & $P$ & $\begin{array}{l}\text { Level } 1 \\
\bar{X} \pm \text { SD }\end{array}$ & $\begin{array}{c}\text { Level2 } \\
\bar{X} \pm \text { SD }\end{array}$ & $p$ \\
\hline \multirow{4}{*}{$\mathrm{RB}$} & LGL & $0.997 \pm 0.54$ & $0.657 \pm 0.07$ & 0.465 & $0.683 \pm 0.2$ & $1.218 \pm 1.06$ & 0.465 \\
\hline & MGL & $0.855 \pm 0.50$ & $0.519 \pm 0.06$ & 0.273 & $0.737 \pm 0.25$ & $1.131 \pm 1.06$ & 0.715 \\
\hline & LGR & $0.685 \pm 0.31$ & $0.645 \pm 0.34$ & 0.715 & $0.669 \pm 0.21$ & $1.134 \pm 0.79$ & 0.068 \\
\hline & MGR & $1.096 \pm 0.82$ & $0.627 \pm 0.22$ & 0.068 & $0.861 \pm 0.29$ & $1.183 \pm 0.93$ & 0.715 \\
\hline \multirow{4}{*}{ RNB } & LGL & $0.851 \pm 0.36$ & $0.75 \pm 0.18$ & 0.273 & $0.848 \pm 0.33$ & $1.099 \pm 0.87$ & 0.715 \\
\hline & MGL & $0.894 \pm 0.15$ & $0.621 \pm 0.24$ & 0.068 & $0.797 \pm 0.3$ & $0.975 \pm 0.81$ & 0.715 \\
\hline & LGR & $0.78 \pm 0.2$ & $0.55 \pm 0.13$ & 0.144 & $0.881 \pm 0.18$ & $1.039 \pm 0.78$ & 0.06 \\
\hline & MGR & $0.985 \pm 0.24$ & $0.547 \pm 0.09$ & 0.068 & $0.693 \pm 0.15$ & $1.114 \pm 0.8$ & 0.715 \\
\hline \multirow{4}{*}{ LR } & LGL & $0.746 \pm 0.18$ & $0.55 \pm 0.08$ & 0.068 & $0.636 \pm 0.04$ & $0.837 \pm 0.58$ & 0.715 \\
\hline & MGL & $0.745 \pm 0.16$ & $0.501 \pm 0.05$ & 0.068 & $0.634 \pm 0.09$ & $0.781 \pm 0.57$ & 0.715 \\
\hline & LGR & $0.671 \pm 0.06$ & $0.547 \pm 0.05$ & 0.068 & $0.652 \pm 0.13$ & $0.727 \pm 0.24$ & 0.715 \\
\hline & MGR & $0.89 \pm 0.26$ & $0.587 \pm 0.05$ & 0.068 & $0.721 \pm 0.12$ & $0.713 \pm 0.25$ & 0.715 \\
\hline \multirow{4}{*}{ LL } & LGL & $0.897 \pm 0.36$ & $0.643 \pm 0.05$ & 0.465 & $0.673 \pm 0.06$ & $0.838 \pm 0.47$ & 0.715 \\
\hline & MGL & $0.864 \pm 0.28$ & $0.634 \pm 0.11$ & 0.273 & $0.795 \pm 0.13$ & $0.863 \pm 0.31$ & 0.715 \\
\hline & LGR & $0.773 \pm 0.27$ & $0.521 \pm 0.05$ & 0.273 & $0.766 \pm 0.27$ & $0.713 \pm 0.19$ & 0.273 \\
\hline & MGR & $0.724 \pm 0.18$ & $0.598 \pm 0.16$ & 0.465 & $0.743 \pm 0.31$ & $0.885 \pm 0.42$ & 0.715 \\
\hline \multirow{4}{*}{$\mathrm{R}$} & LGL & $0.922 \pm 0.4$ & $0.652 \pm 0.22$ & 0.715 & $0.793 \pm 0.17$ & $0.61 \pm 0.14$ & 0.068 \\
\hline & MGL & $1.093 \pm 0.55$ & $0.69 \pm 0.1$ & 0.465 & $1.025 \pm 0.46$ & $0.761 \pm 0.11$ & 0.715 \\
\hline & LGR & $0.989 \pm 0.43$ & $0.706 \pm 0.14$ & 0.465 & $0.876 \pm 0.34$ & $0.796 \pm 0.09$ & 0.465 \\
\hline & MGR & $1.021 \pm 0.42$ & $0.846 \pm 0.105$ & 0.715 & $0.795 \pm 0.22$ & $0.902 \pm 0.07$ & 0.465 \\
\hline
\end{tabular}

Mov.—movement; RB—running with the ball; RNB—running without the ball; LR—lay-up on the right side; LL—lay-up on the left side; R—rebound; Musc.—muscle; LG—lateral gastrocnemius; MG—-medial gastrocnemius; R—right leg; L—left leg.

The level of experience of the athletes studied did not influence the time to peak muscle activity between the two season time-points for each sports movement and muscle. A similarity was found in both levels of athletes studied at each of the season time-points, which is graphically summarized in Figure 3, which shows the time to peak of all muscles' activity for the two athlete levels considering the five basketball movements. 


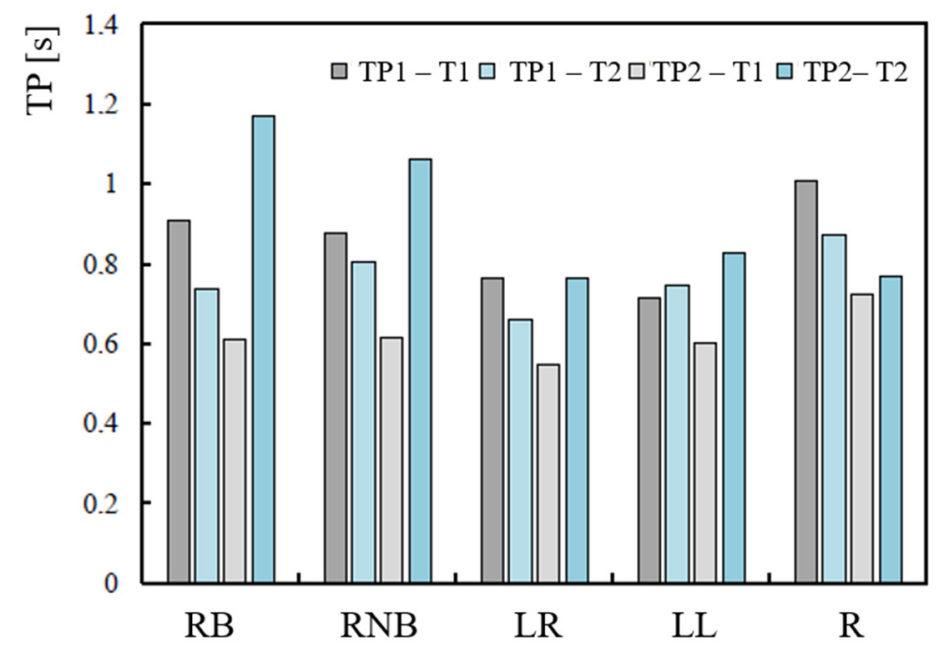

Figure 3. Comparison between two experienced levels in both $\mathrm{T} 1$ and $\mathrm{T} 2$ for TP. TP1-T1-TP for the level 1 athlete in the season T1; TP1-T2-TP for the level 1 in the season T2; TP2-T1-TP for the level 2 in the season T1; TP2-T2-TP for the level 2 in the season T2; RB-running with the ball; RNB-running without the ball; LR-lay-up on the right side; LL-lay-up on the left side; $\mathrm{R}$-rebound.

To verify any differences in the time to peak of muscle activity and the muscle intensity peak for all the muscles independently of the sport movement in each season moment (T1 and T2), the Friedman test was applied (Table 4).

Table 4. Friedman test results for all movements to identify statistically significant differences for $\mathrm{MA}$ and \%MC at the two season time-points.

\begin{tabular}{|c|c|c|c|c|}
\hline \multirow{2}{*}{ Musc } & \multicolumn{2}{|c|}{ T1 } & \multicolumn{2}{|c|}{$\mathrm{T} 2$} \\
\hline & TP & $\% \mathrm{MC}$ & TP & $\% \mathrm{MC}$ \\
\hline & $P$ & $p$ & $p$ & $P$ \\
\hline LGL & 0.795 & 0.554 & 0.165 & 0.132 \\
\hline MGL & $0.029 *$ & 0.575 & $0.004 *$ & 0.541 \\
\hline LGR & 0.071 & $0.029 *$ & 0.281 & 0.664 \\
\hline MGR & 0.247 & 0.144 & 0.394 & 0.897 \\
\hline
\end{tabular}

Due to the observed differences in two muscles (MGL and LGR), a new comparison considering the five movements for the two mentioned muscles (Table 5) was performed.

Table 5. Friedman test results to identify statistically significant differences for $\mathrm{TP}$ and $\% \mathrm{MC}$, for the two season time-points, and for the five movements of two muscles.

\begin{tabular}{|c|c|c|c|c|c|c|c|c|c|c|}
\hline & \multirow{2}{*}{ Mov. } & \multicolumn{3}{|c|}{ RNB } & \multicolumn{2}{|c|}{ LR } & \multicolumn{2}{|c|}{ LL } & \multicolumn{2}{|c|}{$\mathbf{R}$} \\
\hline & & $P$ & MA & $\% \mathrm{MC}$ & MA & $\% \mathrm{MC}$ & MA & $\% \mathrm{MC}$ & MA & $\% \mathrm{MC}$ \\
\hline & RB & $\begin{array}{l}\text { MGL } \\
\text { LGR }\end{array}$ & $>0.05$ & $>0.05$ & $>0.05$ & $0.046 *$ & $>0.05$ & $>0.05$ & 0.073 & 0.171 \\
\hline & RNB & $\begin{array}{l}\text { MGL } \\
\text { LGR }\end{array}$ & & & $>0.05$ & $>0.05$ & $>0.05$ & $>0.05$ & $>0.05$ & $>0.05$ \\
\hline 11 & LR & $\begin{array}{l}\text { MGL } \\
\text { LGR }\end{array}$ & & & & & $>0.05$ & 0.369 & $0.046^{*}$ & $>0.05$ \\
\hline & LL & $\begin{array}{l}\text { MGL } \\
\text { LGR }\end{array}$ & & & & & & & $>0.05$ & $>0.05$ \\
\hline $\mathrm{T} 2$ & $\begin{array}{c}\text { RB } \\
\text { RNB } \\
\text { LR } \\
\text { LL }\end{array}$ & $\begin{array}{l}\text { MGL } \\
\text { MGL } \\
\text { MGL } \\
\text { MGL }\end{array}$ & $>0.05$ & & $\begin{array}{l}0.526 \\
0.526\end{array}$ & & $\begin{array}{l}>0.05 \\
>0.05 \\
0.046^{*}\end{array}$ & & $\begin{array}{c}0.736 \\
0.736 \\
0.002 * \\
>0.05\end{array}$ & \\
\hline
\end{tabular}

Mov—movement; RB—running with the ball; RNB—running without the ball; LR—lay-up on the right side; LL—lay-up on the left side; $\mathrm{R}$-rebound; * $p \leq 0.05$. 
Differences were found for LGR between RB and LR and for MGL between LR and R, LR and LL, and LR and R.

\section{Discussion}

The main objective of this study was to investigate the gastrocnemius activation during the competitive season in five different movements of the basketball game in women athletes with different levels of experience. For that purpose, surface electromyography was used to evaluate the time to peak of muscle activity (TP) and the muscle intensity peak (\%MC). The obtained results (Table 2) show that rebound (R) is the movement for which the sEMG signal reaches the highest value for TP in T1 of the season, corresponding to the only movement that has no associated running in the five movements studied. The TP values obtained in the case of level 1 athletes when comparing T2 with T1 are higher for RB and RNB and lower for R, while the other two movements remain almost constant. For \%MC, the T1 values are greater than the T2 ones, except in the case of R, for which they are lower. Statistical differences were observed for the medial gastrocnemius in the case of RNB, which agrees with Cibulka et al. [42], who observed that the sEMG activation was greater for the MG than the LG when standing and performing a heel raise. In T2, the RB and RNB show higher values of $\mathrm{TP}$, since both are running movements over a long distance and require an effort of concentration and superior focus, which can lead to a performance that is closer to what happens in the real game and is therefore more natural, thus leading to higher TP values. As well as this, the movements associated with accelerations and decelerations require high muscle recruitment, which is in accordance with Hewit et al. [43], who stated that the primary muscles used for deceleration are the quadriceps and gastrocnemius.

Regarding the experience level of the athletes (Table 3) in relation to only the TP value, concerning the two season time-points, it can be observed that the level 1 athletes show higher values for $\mathrm{T} 1$ than the level 2 athletes for the five movements, and for both levels, $\mathrm{R}$ is the movement that presents a larger value. Nevertheless, while in the case of the level 1 athletes, a decrease in the TP value is present for T2 relative to T1, the opposite is observed for the level 2 athletes. Pakosz et al. [29] evaluated the arm during free throws and concluded that players of higher training experience have a lower time of muscle activation because the time necessary to promote the movement is shorter for advanced players [31]. In addition, Abe et al. [32] verified for basketball dribbling that experts showed lower sEMG arm signals than the beginners. In the present study, this is observed only at T2 of the season, which can be explained by the fact that, as the season progresses, more experienced athletes (1) improve their technique more easily, and, consequently, they need less time to perform the movement. Table 3 shows statistical differences between T1 and T2 when only RNB and LR were assessed, and no significant differences were evaluated for the different muscles analyzed.

The influence of all movements in TP and \%MC for the four muscles under analysis (Table 4) presented statistically significant differences in TP for MGL in T1 and T2 and in $\% \mathrm{MC}$ for LGR in T1. It can be verified from Table 5 that significant differences between movements for the TP variable occur only between LR and LL for T2 and between LR and $\mathrm{R}$ for both season time-points. \%MC varies only between RB and LR for T1, while for $\mathrm{T} 2$, no statistically significant differences between movements are identified. Although the difference is almost non-existent, at T1, practically all p values are greater than 0.05 , concluding that for this period of the season, in comparison with T2, the sEMG values are more homogeneous between all movements. At the beginning of the season, athletes are more concerned with recovering their physical form than improving their technique. As the season progresses, more experienced athletes move with greater precision, reducing muscle activation time, which is in agreement with Pakosz and Abe et al. [30,32]. 


\section{Conclusions}

Our main interest in this study was to examine possible differences in the muscular activity within gastrocnemius muscles between five principal movements in basketball practice, at two season time-points, performed by basketball players with different levels of experience. The analysis of the results obtained showed that no statistically significant differences occurred between the two season time-points. However, for TP, T2 of the season presents greater values when compared with $\mathrm{T} 1$, but \%MC has an inverse trend, presenting higher values for $\mathrm{T} 1$ compared with $\mathrm{T} 2$. In addition, no statistically significant differences arose when comparing the four muscles (LGL, MGL, LGR, and MGR). Considering the five different movements, it is possible to conclude that in the case of $\mathrm{T} 2$, the results are more homogeneous than in the case of T1 for the more experienced athletes. At T1 and T2 of the season, rebound (R) shows greater TP values than the other four movements for level 1 athletes, but in the case of level 2 athletes, the greater value is obtained for R in T1 of the season, whereas for T2 of the season, the higher values are observed for RB and RNB. The level of experience of the athletes has an important role in TP, verifying that for T1, the athletes with more experience (level 1) present higher values when compared with those of level 2, but with the advance of the season (T2), this trend is inverted.

The obtained results can be used by coaches and athletes to help them to define drivespecific training programs adjusted to the time of the season and the performance level of athletes. According to the athletes' characteristics, referring to the muscular activity, coaches can prepare specific exercises to optimize the muscular performance of each one. Future work will study a larger sample and professional athletes to establish differences between professional and amateur athletes in these and other basketball movements.

Author Contributions: M.A.C., L.R. and A.M.A. conceived and designed the study; C.M.A. performed the tests, analyzed the results, and helped to write the manuscript; M.A.C., L.R. and A.M.A. participated in the research work and helped to write the manuscript. C.M.A., M.A.C., L.R., R.M. and A.M.A. contributed to the acquisition, analysis, and interpretation of data and helped to write the manuscript. All authors have read and agreed to the published version of the manuscript.

Funding: This research was sponsored by FEDER funds through the program COMPETE-Programa Operacional Factores de Competitividade, and by national funds through FCT-Fundação para a Ciência e a Tecnologia, under Project UIDB/00285/2020 and Mais Centro Program, Center Region Coordination Committee of EU through European Regional Development Fund.

Institutional Review Board Statement: The study was conducted according to the guidelines of the Declaration of Helsinki, and approved by the Ethics Committee of the Polytechnic of Coimbra (CEPC 26/2018)

Informed Consent Statement: Informed consent was obtained from all subjects involved in the study.

Data Availability Statement: The data presented in this study are available on request from the corresponding author. The data are not publicly available due to restrictions eg privacy or ethics.

Conflicts of Interest: Authors declare no conflict of interest.

\section{References}

1. Mickevičius, M.; Degens, H.; Kesminas, R.; Rutkauskas, S.; Satkunskiene, D.; Vadopalas, K.; Pukenas, K.; Jürimäe, J.; Skurvydas, A.; Kamandulis, S. Early anterior knee pain in male adolescent basketball players is related to body height and abnormal knee morphology. Phys. Ther. Sport 2018, 32, 273-281. [CrossRef] [PubMed]

2. Haskell, W.L.; Lee, I.M.; Pate, R.R.; Powell, K.E.; Blair, S.N.; Franklin, B.A.; Macera, C.A.; Heath, G.W.; Thompson, P.D.; Bauman, A. Physical activity and public health: Updated recommendation for adults from the American College of Sports Medicine and the American Heart Association. Med. Sci. Sports Exerc. 2007, 39, 1423-1434. [CrossRef] [PubMed]

3. Kong, Z.; Qi, F.; Shi, Q. The influence of basketball dribbling on repeated high-intensity intermittent runs. J. Exerc. Sci. Fit. 2015, 13, 117-122. [CrossRef] [PubMed]

4. Castagna, C.; Abt, G.; Manzi, V.; Annino, G.; Padua, E.; D'Ottavio, S. Effect of recovery mode on repeated sprint ability in young basketball players. J. Strength Cond. Res. 2008, 22, 923-929. [CrossRef] [PubMed] 
5. Piedra, A.; Peña, J.; Ciavattini, V.; Caparrós, T. Relationship between injury risk, workload, and rate of perceived exertion in professional women's basketball. Apunts Sports Med. 2020, 55, 71-79. [CrossRef]

6. Abdelkrim, N.B.; El Fazaa, S.; El Ati, J. Time-motion analysis and physiological data of elite under-19-year-old basketball players during competition. Br. J. Sport Med. 2007, 41, 69-75. [CrossRef]

7. Figueira, B.; Gonçalves, B.; Abade, E.A.; Paulauskas, R.; Masiulis, N.; Sampaio, J. Effects of a 4-week combined sloped training program in young basketball players' physical performance. Sci. Sports 2019, 35, e1-e172. [CrossRef]

8. Oliver, J.A. Basketball Fundamentals; Human Kinetics Publishers: Champaign, IL, USA, 2003; pp. 49-51.

9. Borowski, L.A.; Yard, E.E.; Fields, S.K.; Comstock, R.D. The Epidemiology of US High School Basketball Injuries, $2005-2007$. Epidemiol. US High Sch. Basketb. Inj. 2008, 36, 2328-2335. [CrossRef]

10. Caine, D.; Maffulli, N.; Caine, C. Epidemiology of Injury in Child and Adolescent Sports: Injury Rates, Risk Factors, and Prevention. Clin. Sport Med. 2008, 27, 19-50. [CrossRef]

11. Frisch, A.; Croisier, J.L.; Urhausen, A.; Seil, R.; Theisen, D. Injuries, risk factors and prevention initiatives in youth sport. Br. Med. Bull. 2009, 92, 95-121. [CrossRef]

12. Cumps, E.; Verhagen, E.; Meeusen, R. Prospective epidemiological study of basketball injuries during one competitive season: Ankle sprains and overuse knee injuries. J. Sports Sci. Med. 2007, 6, 204-211. [PubMed]

13. Baker, H.; Rizzi, A.; Athiviraham, A. Injury in the Women's National Basketball Association (WNBA) From 2015 to 2019. Arthrosc. Sport Med. Rehabil. 2020, 2, e213-e217. [CrossRef] [PubMed]

14. Siu, R.; Ling, S.K.K.; Fung, N.; Pak, N.; Yung, P.S.H. Prognosis of elite basketball players after an Achilles tendon rupture. Asia-Pac. J. Sport Med. Arthrosc. Rehabil. Technol. 2020, 21, 5-10.

15. Deitch, J.R.; Starkey, C.; Walters, S.L.; Moseley, J.B. Injury risk in professional basketball players: A comparison of Women's National Basketball Association and National Basketball Association athletes. Am. J. Sports Med. 2006, 34, 1077-1083. [CrossRef]

16. Agel, J.; Arendt, E.A.; Bershadsky, B. Anterior cruciate ligament injury in national collegiate athletic association basketball and soccer: A 13-year review. Am. J. Sports Med. 2005, 33, 524-530. [CrossRef]

17. Klyne, D.M.; Keays, S.L.; Bullock-Saxton, J.E.; Newcombe, P.A. The effect of anterior cruciate ligament rupture on the timing and amplitude of gastrocnemius muscle activation: A study of alterations in EMG measures and their relationship to knee joint stability. J. Electromyogr. Kinesiol. 2012, 22, 446-455. [CrossRef]

18. Morgan, K.D.; Donnelly, C.J.; Reinbolt, J.A. Elevated gastrocnemius forces compensate for decreased hamstrings forces during the weight-acceptance phase of single-leg jump landing: Implications for anterior cruciate ligament injury risk. J. Biomech. 2014, 47, 3295-3302. [CrossRef]

19. Dewar, R.A.; Arnold, G.P.; Wang, W.; Drew, T.S.; Abboud, R.J. Comparison of 3 ankle braces in reducing ankle inversion in a basketball rebounding task. Foot (Edinb.) 2019, 39, 129-135. [CrossRef]

20. McKay, G.D.; Goldie, P.A.; Payne, W.R.; Oakes, B.W. Ankle injuries in basketball: Injury rate and risk factors. Br. J. Sports Med. 2001, 35, 103-108. [CrossRef]

21. Fong, D.T.; Hong, Y.; Chan, L.K.; Yung, P.S.; Chan, K.M. A systematic review on ankle injury and ankle sprain in sports. Sports Med. 2007, 37, 73-94. [CrossRef]

22. Longo, U.G.; Loppini, M.; Berton, A.; Marinozzi, A.; Maffulli, N.; Denaro, V. The FIFA 11+ program is effective in preventing injuries in elite male basketball players: A cluster randomized controlled trial. Am. J. Sports Med. 2012, 40, 996-1005. [CrossRef] [PubMed]

23. Klem, N.R.; Wild, C.Y.; Williams, S.A.; Ng, L. Effect of External Ankle Support on Ankle and Knee Biomechanics During the Cutting Maneuver in Basketball Players. Am. J. Sports Med. 2017, 45, 685-691. [CrossRef] [PubMed]

24. Vieira, T.M.M.; Minetto, M.A.; Hodson-tole, E.F.; Botter, A. Human Movement Science How much does the human medial gastrocnemius muscle contribute to ankle torques outside the sagittal plane? Hum. Mov. Sci. 2013, 32, 753-767. [CrossRef] [PubMed]

25. Sikora, M.; Paszkiel, S. Muscle activity measurement using visible light and infrared. IFAC Pap. 2019, 52, 329-334. [CrossRef]

26. Massó, N.; Rey, F.; Romero, D.; Gual, G.; Costa, L.; Germán, A. Surface electromyography applications in the sport. Apunts Med. Esport 2010, 45, 127-136. [CrossRef]

27. Henry, S.M.; Fung, J.; Horak, F.B. EMG responses to maintain stance during multidirectional surface translations. J. Neurophysiol. 1998, 80, 1939-1950. [CrossRef]

28. Sanderson, D.J.; Martin, P.E.; Honeyman, G.; Keefer, J. Gastrocnemius and soleus muscle length, velocity, and EMG responses to changes in pedalling cadence. J. Electromyogr. Kinesiol. 2006, 16, 642-649. [CrossRef]

29. Pakosz, P.; Konieczny, B.E.M. Time Analysis of Muscle Activation during Basketball Free Throws. Cent. Eur. J. Sport Sci. Med. 2016, 15, 73-79. [CrossRef]

30. Pakosz, P. EMG signal analysis of selected muscles during shots and passes in basketball. J. Health Promot. Recreat. 2011, 1, 9-14.

31. Zachry, T.; Wulf, G.; Mercer, J.; Bezodis, N. Increased movement accuracy and reduced EMG activity as the result of adopting an external focus of attention. Brain Res. Bull. 2005, 30, 304-309. [CrossRef]

32. Abe, S.; Nozawa, T.; Kondo, T. A Proposal of EMG-Based Training Support System for Basketball Dribbling. In Human Interface and the Management of Information. Designing Information Environments. Human Interface; Smith, M.J., Salvendy, G., Eds.; Lecture Notes in Computer Science; Springer: Berlin/Heidelberg, Germany, 2009; Volume 5617. [CrossRef] 
33. Hanks, M.; Oliver, G. Muscle Activation Patterns in Wheelchair Basketball Athletes with and without Physical Disability. Int. J. Physiatry 2018, 4, 013. [CrossRef]

34. Uzun, S.; Pourmoghaddam, A.; Hieronymus, M.; Thrasher, T.A. Evaluation of muscle fatigue of wheelchair basketball players with spinal cord injury using recurrence quantification analysis of surface EMG. Eur. J. Appl. Physiol. 2012, 112, $3847-3857$. [CrossRef] [PubMed]

35. Roman-Liu, D.; Bartuzi, P. Influence of type of MVC test on electromyography measures of biceps brachii and triceps brachii. Int. J. Occup. Saf. Ergon. 2018, 24, 200-206. [CrossRef] [PubMed]

36. Mok, N.W.; Yeung, E.W.; Cho, J.C.; Hui, S.C.; Liu, K.C.; Pang, C.H. Core muscle activity during suspension exercises. J. Sci. Med. Sport 2015, 18, 189-194. [CrossRef]

37. Hermens, H.J.; Freriks, B.; Merletti, R.; Stegeman, D.; Blok, J.; Rau, G.; Disselhorst-Klug, C.; Hägg, G. European Recommendations for Surface ElectroMyoGraphy. Roessingh Res. Dev. 1999, 8, 13-54.

38. Arendt-Nielsen, L.; Graven-Nielsen, T.; Svarrer, H.; Svensson, P. The influence of low back pain on muscle activity and coordination during gait: A clinical and experimental study. Pain 1996, 64, 231-240. [CrossRef]

39. van Hedel, H.; Tomatis, L.; Muller, R. Modulation of leg muscle activity and gait kinematics by walking speed and bodyweight unloading. Gait Posture 2006, 24, 35-45. [CrossRef]

40. Ghasemi, A.; Zahediasl, S. Normality tests for statistical analysis: A guide for non-statisticians. Int. J. Endocrinol. Metab. 2012, 10, 486-489. [CrossRef]

41. Guerino, M.; Vicente, R.C.; Cesário, M.D.; Guirro, R. Cold-water immersion alters muscle recruitment and balance of basketball players during vertical jump landing. J. Sports Sci. 2015, 34, 1-10. [CrossRef]

42. Cibulka, M.T.; Wenthe, A.; Boyle, Z.; Callier, D.; Schwerdt, A.; Jarman, D.; Strube, M.J. Variation in medial and lateral gastrocnemius muscle activity with foot position. Int. J. Sports Phys. Ther. 2017, 12, 233-241.

43. Hewit, J.; Cronin, J.; Button, C.; Hume, P. Understanding Deceleration in Sport. Strength Cond. J. 2011, 33, 47-52. [CrossRef] 